\title{
Loss of humanism and ethics in the medical profession: is it a utopia to restore them?
}

Undoubtedly, the attitude of the medical profession towards patient care is currently remarkably different from what it used to be. The multiple and outstanding changes in medicine in the last decades have had an impact on this process, especially after the Second World War, resulting in many benefits in health care, such as disease prevention and a better outcome in the treatment of severe disorders. However, I should point out that these achievements mainly occurred in developed countries while this did not happen in many other countries where even today poor populations suffer from many diseases that make them live a totally inadequate quality of life. This inequality is a challenge to be overcome.

Likewise, these changes in medicine also modified many of the virtues that had the medical profession in its "golden age", from the last decades of the $19^{\text {th }}$ until the mid- $20^{\text {th }}$ century. In those years, doctors understood that what was essential was to understand what patients needed and to support them, listen to them without haste and provide them with the best possible care. Early in the $20^{\text {th. }}$ century, doctors stopped prescribing harmful treatments, which frequently caused death, and even though they only had just a few effective drugs (digitalis, salicylate, morphine) at their disposal, with their compassionate attitude they earned the trust of the people and achieved much prestige.

Unfortunately, changes in medical practice in the last decades have not been promising and neither are they today, since they are getting worse and worse. This progressively contributed to a loss of dignity of the medical profession and to the very poor opinion that society presently has of doctors.

One of the most critical aspects is the devalued physician-patient relationship leading to several problems in those who usually rely on doctors. When the appointment is over, they feel alone because they could not get answers to their problems; consequently, their trust is undermined. I should point out that this attitude also makes physicians make more mistakes, and then patients are both let down by their physicians and also at greater risk of suffering a consequence, sometimes very severe, due to the physicians' error. To ensure patient safety, physicians will only be able to reduce the incidence of errors and adverse events if patients are actively involved.

In a recent essay, Michael L Millenson underscores several negative aspects in the care of patients by physicians. I would like to highlight this sentence that perfectly embodies what is happening in our profession today: "Patient centred care is being subsumed by collaborative health, enabled by sweeping technological, economic, and social changes. Doctors are losing some of their power and will have to alter their behavior to retain public trust". ${ }^{1}$

Additionally, different characteristics related to physicians' attitudes have been described, and those who continue struggling to restore humanism are the ones who are still advocating for a substantial improvement in health care delivery today..$^{2-5}$

What are the causes of this poor relationship with patients? The exponential growth in mercantilism associated with the overwhelming technological advances that are continuously evolving and being misused are, in my judgment, the most deleterious factors that have led us to the loss of humanism and ethics.

However, we should undoubtedly keep hope alive, as the famous Argentine writer Jorge Luis Borges stated in a manner very typical of him: "Maybe ethics is a science that has disappeared from the whole world. It does not matter, we will have to invent it again". Also, it is necessary for physicians and patients to be aware of the limitations of medicine and embrace the uncertainty that lies beyond. "Only because we do not understand everything and because we cannot control the future is it possible to live", says Iona Heath in an essay. One of the most remarkable evils in current medicine is not accepting uncertainty, since by assuming that they know it all (being unaware of their ignorance), physicians think they have made the appropriate diagnosis or the right decision, when this is not the case.

Evidence-based medicine is also to be considered. Its misconception has given rise to several issues in medical practice. ${ }^{3,6}$ Frequently, physicians praise evidence over everything else, which is undoubtedly a mistake, since our obsession with evidence can lessen our humanity during the medical visit. Evidence does not equal absolute truth, and has limitations, as shown in various publications. We need to bear this 
in mind because, otherwise, the gap between evidence and humanity -which patients seek and need-will deepen. We, physicians, are not all scientists, and every patient presents a unique challenge, which cannot be approached only with the findings of a randomized clinical trial. That is why to provide adequate, consistent and better-balanced care, patient health requires a new approach from physicians to bridge the gap between evidence and humanism.

Finally, to answer the question posed by the title of this editorial as to whether it is a utopia to restore humanism, in my opinion, it is not: we cannot give up; we must go on advocating for better patient care. Dr. Plant et al., ${ }^{7}$ recommends that, in order to meet this challenge, we need to reflect on our own journey through medicine and remember the crucial moments at which the medical profession renewed its commitment to old values.

These moments may refer to the principles that help us rediscover elements which are inherent to medical practice and regain the acknowledgment which society granted physicians serving those in pain and need of care. This attribute, based on our honest concern for the core significance of human values in every facet of professional life, is known as humanism, often defined as the presence of empathy, altruism, humility and compassion. In this regard, William Osler remarked: "It is much more important to know what sort of a patient has a disease than what sort of a disease a patient has".

It is imperative that we return to the path to a medicine based on the needs of the people and not that which leads us to consider first the profit in our task that will unfailingly distance us from the attributes that we must maintain.

It is critical that we do not stray from the path to medicine based on people's needs instead of a money-driven practice, which will definitely pull us away from the attributes we need to uphold. Perhaps it would be appropriate to advice physicians that, in order to understand medicine, first they should read Don Quixote by Cervantes, as did the English doctor Thomas Sydenham telling Richard Blackmore, the King's personal physician. In fact, there is much medical knowledge depicted in the book and, strikingly, although it was written over 500 years ago, it criticizes the negative aspects of medicine, as clearly pointed out by the following excerpt: "There's many a one that kills the patient he treats, yet insists on being paid even though all he does is write out a prescription for certain medicines".

\section{José M. Ceriani Cernadas} Editor in Chief

http:/ / dx.doi.org/10.5546/ aap.2017.eng.522

To cite: Ceriani Cernadas JM. Loss of humanism and ethics in the medical profession: is it a utopia to restore them? Arch Argent Pediatr 2017;115(6):522-523.

\section{REFERENCES}

1. Millenson ML. When "patient centred" is nolonger enough: the challenge of collaborative health: an essay by. BMJ. 2017;358:j3048.

2.- Goodlee F. Diagnostic skill and patient centred care. BMJ. 2014;349:g6665.

3. Heath L. How medicine has exploited rationality at the expense of humanity: an essay by Iona Heath. BMJ. 2016;355:i5705.

4. Rosenthal DI, Verghese V. Meaning and the Nature of Physicians' Work. N Engl J Med. 2016;375(19):1813-5.

5. TsaiJW.Making Conscious the Unconscious. JAMA Pediatr. 2017;171(8):725-6.

6. Abbasi K. We need more humanity as well as better evidence. BMJ. 2016;355:i5907.

7. Plant J, Barone MA, Serwint JR, et al. Taking Humanism Back to the Bedside. Pediatrics. 2015;136(5):828-30. 